\title{
Wake Induced Power Losses in Wind Farms
}

\author{
Veena R, Manuel S M, Mathew S, Petra M I
}

\begin{abstract}
With the steady growth in the wind power sector in the past decade and the projected expansions in the future, wind energy plays a significant role in the Global clean energy scenario. When wind turbines operate in clusters as in wind farms, downwind turbines experience wake losses caused by the upwind turbines. For the efficient design and successful management of wind energy projects, these wakes induced power losses within the turbine arrays are to be analyzed and understood. In this paper, we review different approaches, both based on kinematic and flow models, in quantifying the wake induced velocity and power deficits within wind farms. Under the kinematic approach, Jensen, Larsen and Frandsen models are described. Ainslie, RANS, DNS and LES models are covered under the CFD based flow approach. The deep array effect, which is being experienced in large sized wind farms, are also discussed and models developed to estimate the deep array wake losses are reviewed. Need for new methods and approaches in quantifying the deep array losses are highlighted in the paper.
\end{abstract}

Keywords: Windfarms; Wake losses; Deep array effect, Computational Fluid Dynamics.

\section{INTRODUCTION}

The wind energy sector is growing rapidly. As a result, the share of wind generated electricity in the power grids around the world has significantly increased. For example, with 51.3 GW of new installations, the global wind power capacity has reached up to $591 \mathrm{GW}$ by 2018 [1]. Wind continues to retain its prominence among the renewables as the compound annual growth rate (CAGR) in this sector, over the past five years is around $13 \%$ [1]. With all these installations, wind could provide 1,270 TWh of electricity to the global grids [2]. Although most of these contributions are from onshore projects, the offshore wind energy sector is also expanding aggressively. For example, an offshore capacity of $4.5 \mathrm{GW}$ has been added by 2018, with which the cumulative offshore installations could reach $23 \mathrm{GW}$ [1]. Several ambitious projects with large scale wind power systems, both onshore

Revised Manuscript Received on February 05, 2020.

* Correspondence Author

Veena R*, Institute of Applied Data Analytics, Faculty of Integrated Technologies, University of Brunei Darussalam, Brunei Darussalam. Email: veenawind@gmail.com>

Manuel S M, Institute of Applied Data Analytics, Faculty of Integrated Technologies, University of Brunei Darussalam, Brunei Darussalam. Email: manuelmathewsm@gmail.com

Mathew S, Faculty of Engineering and Science, University of Agder, Norway Email: sathyajith.mathew@uia.no>

Petra M I, Faculty of Integrated Technologies, University of University of Brunei Darussalam, Brunei Darussalam. Email: iskandar.petra@ubd.edu.bn

(c) The Authors. Published by Blue Eyes Intelligence Engineering and Sciences Publication (BEIESP). This is an open access article under the CC BY-NC-ND license (http://creativecommons.org/licenses/by-nc-nd/4.0/) and offshore, are at different stages of planning and development around the world.

One of the challenges in developing and managing wind energy farms is understanding the power losses due to the wake effect. As the wind passes through the upstream turbines in a wind farm, due to the energy extraction by the first-row turbines and churning effect of the rotating blades, the flow will get weakened and disturbed, which is generally termed as the wake effect. As a result of wakes, the power produced by the first row of downwind turbines would considerably be less than the upwind turbines. This deficit pattern continues for all the successive turbines after the first wake field. In case of some large wind farms, the power deficits due to wake can be as high as $20-40 \%$ [3]. As a result, the annual energy production could suffer losses up to $15 \%$ [4]. Wake effect not only reduces the productivity and thereby economic merits of the wind farm, but also limits the lifetime of the wind turbines as shown in [5]-[8].

Hence, understanding the wake propagation pattern at the wind flow condition prominent in a prospective site is essential in wind farm designs. Once the wake pattern is estimated, the designer can geographically position the turbines within the farm in such a way that the wake induced power losses are minimized. Similarly, wake estimation is important in developing efficient tools for wind farm management, for example in wind power forecasting and prognostics.

In this paper, we review different wake models used by the industry to estimate wind farm wakes. The deep array effect, which is experienced in large wind farms are also discussed briefly.

\section{TYPES OF WAKES}

The first systematic analysis of wakes induced by wind turbines was by Lissaman [9]. This is followed by the experimental studies by [10],[11]. The wakes experienced behind the wind turbine can be of two types - the near wake and the far wake. The near wake region refers to the immediate disturbance behind the rotor, approximately up to one to five times the rotor diameter. This wake, which is influenced by the rotor characteristics such as the number of blades, blade aerodynamics and tip vortices, radially expands until it is 


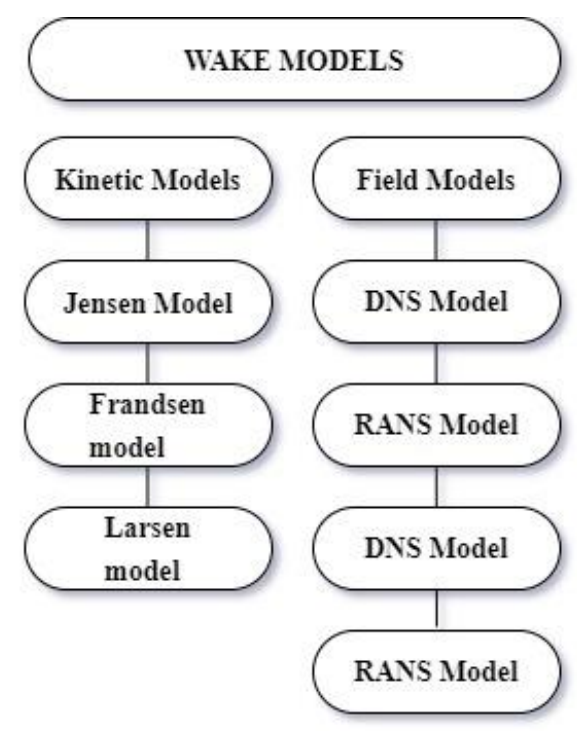

Fig. 1 Classification of wake models

fully developed. An extensive analysis of near wake effects is presented in [12],[13].

On the other hand, the mechanism of far wakes are different. In far wakes, the velocity initially drops and gradually regains at the downstream of the turbine. The velocity deficits are mostly recovered before encountering to another, if the turbines are placed at sufficient distances. In larger wind farms, the 'Deep Array Effect', where the turbine array itself act as a roughness contributor within the planetary boundary layer, will also contribute to the wake losses [14]. Being more important in the wind farm design and management, discussions in this paper will be limited the far wakes.

\section{METHODS FOR ESTIMATING WAKE LOSSES}

Models which are conventionally used for quantifying the wake effect in wind farms can broadly be classified as kinematic models and field models. There are different variations for these models, for example see [13],[15], which also broadly comes under one of these two approaches. These classifications are shown in Fig. 1 and briefly described in the following sections.

\section{A. Kinematic Models}

These models, which are also termed as explicit models or analytical models, were the first models introduced for wind turbine wake estimation [16]. There are three well-established kinematic models available today. They are Jensen model [17], Larsen model [18] and Frandsen model [19]. These models assess the flow field using the momentum equation to model reduction in velocity due to the wake behind a turbine. This approach disregards the initial wake expansion region and the initial turbulence intensity and hence neglects the near wake effects. These models are briefly described below.

\section{Jensen model}

This wake model is the oldest wake model which was developed by N.O Jensen in 1983 [17] and extended by [20]. The models were further improved to incorporate turbulence models [21]. Recently, [22] improved the Jensen model by incorporating the effects of partial shadowing, yaw misalignment and inconsistent wind conditions.
The Jensen model considers that the wake symmetric expands proportionally with the flow after the turbine, where the initial wake diameter is taken as the turbine rotor diameter. For a given distance in the downstream, the velocity is assumed constant as the wake spreads in both the vertical and lateral directions, giving the wake a 'top-hat' velocity profile. In its general form, Jensen's model estimates the wake induced velocity deficit by

$$
u=u_{0}\left[1-\frac{1-\sqrt{1-C_{T}}}{\left(1+\frac{2 k X}{D}\right)^{2}}\right]
$$

and the wake diameter as

$$
D_{W}=D+2 k X
$$

where $u_{0}$ is the free (undisturbed) velocity, $C_{T}$ is the turbine thrust coefficient, $X$ is the downstream distance from the rotor, $D$ is the rotor diameter and its unit is meter, $D_{w}$ is the wake diameter and $k$ is the wake decay constant. In the model, the wake decay constant is used to characterize how the wake diameter expands and the velocity deficit is recovered. In the case of onshore wind farms, $k$ can be taken as 0.075 , while for offshore, 0.04 is a good approximation for $k$ [23].

Although the Jensen model does not specifically consider the turbulence, the wake decay constant does relate ambient turbulence into the model since it is a function of the terrain roughness. Low decay constant indicates low turbulence and vice versa. Although the wake decay constant is influential for specific wind directions calculations, the errors will become negligible when all directions are included [20]. Similarly, though the complete shadowing of the downstream turbine is the main concern in Jenson's wake modelling, partial shadowing should also be included in the analysis [22]. This is mainly due to the yaw misalignment due to the differences in the yawing speed and the speed at which the wind direction changes. As a result, turbines could be misaligned with direction during operation. Two methods for estimating this time delay has been proposed by [24],[25]. Based on this, a correction has been proposed by [22].

\section{Larsen model}

A simple wake computation procedure was introduced by Larsen which is being used wind some wind farm design tools [18]. In this method, width of the wake and the mean velocity profile within the wake are solved using the Prandtl turbulent boundary layer model. The closed form solution can be arrived by assuming a self-similar velocity profile thereby using Prandtl's mixing length theory. In this model, the axis-symmetric form is made by further assuming the flow as incompressible and stationary with the thin wind shear approximation. Larsen has introduced a first-order as well as a second-order approximate solution to the boundary layer equations [26], out of which the second order is suitable for solving the double dip in the velocity reduction profile of the near wake. The first order equation of the rotor wake radius is given as 


$$
R_{w}(x)=\left(\frac{35}{2 \pi}\right)^{\frac{1}{5}}\left(3 c_{1}^{2}\right)^{\frac{1}{5}}\left(C_{T} A\left(x+x_{0}\right)\right)^{\frac{1}{3}}
$$

where, $C_{T}$ is the thrust coefficient of the turbine and $A$ is the area covered by the rotor.

\section{Frandsen model}

Frandsen Model, also known as the Storpark Analytical Model (SAM), was presented in [19]. This model has the advantage over other kinematic models like Jensen and Larsen as it can model multiple wakes. Developed mainly for offshore wind farms, the Frandsen model relates to layouts with regular array geometry (equidistant turbine spacing within a row and between arrays). The model considers three regimes. The first regime assumes that there is no interaction among neighboring wakes. As the wake flow propagates downstream, it phases into a second regime as two neighboring wakes interact. Further, when the wake flows through an infinitely large wind farm, it enters the third regime where it balances with the boundary layer. Similar to the Jensen model, this model has a 'hat-shaped' velocity deficit profile. The Velocity deficit and Wake diameter are given by

$$
u=\frac{u_{0}}{2}\left[1 \pm \frac{A}{A_{w}} C_{T}\right]
$$

and

$$
D_{W}=D \max \left[\beta, 0.7 \frac{X}{D}\right]^{\frac{1}{2}}
$$

where

$$
\beta=\frac{1-\sqrt{1-C_{T}}}{2 \sqrt{1-C_{T}}}
$$

where $U_{0}$ is the undisturbed velocity, $C_{T}$ is the turbine thrust coefficient, $X$ is the distance from the rotor in the downstream, $D$ is the rotor diameter, $D_{w}$ is the wake diameter, $A$ is the area covered by the rotor, $A_{w}$ is the wake area and $\beta$ the wake expansion coefficient.

In case of multiple wakes resulting from upstream turbines (composite wakes) the model divides the wake into several sections called mosaic tiles. Each tile is thought to have constant (although varying) velocity. The mean wind speed over the rotor area is then solved using a semi-linear method as discussed in [27]

\section{B. Field Models}

Field models calculate the wake losses by analyzing the complete wake flow field through the wind farm using computational fluid dynamics (CFD). These models are categorized in accordance to which technique applied for simulating the wake turbulence. Broadly, these are Ainslie model, Reynolds-averaged Navier-Stokes (RANS) model, Direct Numerical Simulation (DNS) model and Large Eddy Simulations (LES) model.

\section{Ainslie Model}

This wake model is developed by numerically solving the wake differential equations (RANS) using an Eddy Viscosity (EV) wake model for turbulent closure in the velocity deficit [28]. The wake here is considered asymmetrical and fully turbulent, where diffusion and the pressure gradients in the outer flow are not considered. The differential equations can be solved using any finite difference numerical integration scheme [29],[30]. The boundary conditions are taken when the parabolicity is fully developed, i.e. at 2 rotor diameters (after the near wakes), using the Gaussian velocity profile

$$
u=u_{0}\left(1-D_{w} e^{-3.56\left(\frac{r}{b}\right)^{2}}\right)
$$

which is valid for at least 5 rotor diameters downstream. Here

$$
D_{w}=C_{T}-0.005-\left(16 C_{T}-0.5\right) \frac{I}{1000}
$$

Based on wind tunnel experiments, it is shown that, the parameter $I$ is the ambient turbulence intensity (\%) and $C_{T}$ is the thrust coefficient of the turbine. Similar to the Jensen model, through conservation of momentum, Ainslie model can relate the velocity deficit and thrust coefficient by defining the wake width, $b$ as

$$
b=\sqrt{\frac{3.56 C_{T}}{8 D_{w}\left(1-0.5 D_{w}\right)}}
$$

When the Gaussian wake profile was observed to remain consistent with changing width and depth, the solution to the EV in the Ainslie model was simplified, which is named as the Simple Model [30]. Here, the computations needed were only the wake centerline velocity deficits, which is represented by

$$
\frac{d U_{c}}{d x}=\frac{16 \varepsilon\left(U_{c}^{3}-U_{c}^{2}+1\right)}{U_{c} C_{T}}
$$

where

$$
U_{c}=U_{0}\left(1-D_{m}\right)
$$

Here, $u_{0}$ is the free stream velocity, $C_{T}$ is the turbine thrust coefficient, $X$ is the downstream distance from the rotor, $D$ is the rotor diameter, $D_{w}$ is the wake diameter, $A$ is the area covered by the rotor, $A_{w}$ is the wake area and $\beta$ the wake expansion coefficient.

\section{RANS model}

RANS (Reynolds-averaged Navier-Stokes) results from an averaging procedure on the incompressible Navier-Stokes equations. The flow is divided into a mean flow with a fluctuating turbulent component using the models. Here, the computations remain challenging due to the implicit methods required to handle the RANS divergence-free constraints. There are two simplified methods in solving the RANS, namely the parabolic codes and elliptical codes, both derived from the Ainslie Model. Although parabolic codes have the capability for fast computations, it has limitations in terms of predicting the wake centerline and maximum turbulence intensity. Elliptic models, on the other hand, are basically an extension of these parabolic codes and are based the approaches of generalized actuator discs or actuator lines. 


\section{Wake Induced Power Losses in Wind Farms}

\section{DNS model}

With the Reynolds number characterizing the flow field being high, a wide range of turbulent scales must be resolved to fully solve the complete Navier-Stokes equations. DNS (Direct Numerical Simulation) has the capability to resolve these scales. However, these are computationally expensive. Simpler techniques are hence adopted, using models to estimate the effect of any unresolved turbulent scales in the flow, such as RANS and LES.

\section{LES model}

Large Eddy Simulations (LES) is superior to RANS model because it is independent of turbulence models. Two methods exist for LES, the synthesized inlet method and precursor simulation method, where the large turbulent scales are explicitly computed while the smaller scales use some sub-grid scale model. Unlike RANS, the velocity deficit and additional turbulence intensities can be estimated directly in LES and thus its computation is more demanding than RANS.

\section{ANALYSIS OF RESULTS FROM LARGE WIND FARMS}

In the conventional wake models discussed above, it is assumed that the ambient wind is not altered due to the presence of wind turbines. However, this may not be true in case of large wind farms. Presence of large turbines, hundreds in numbers, can influence the planetary boundary layer (lowest layer of the atmosphere) outside the direct wake zone. This two-way interaction between the turbines and atmospheric boundary layer and the resulting deep array effect restrict the wake recovery in large wind farms [31],[32].

Deep array effect can be considered as the cumulative drag imposed by the turbine arrays on the planetary boundary layer [33]. Though the deep array effect exists in both onshore and offshore wind farms of larger size, it was prominently noticed in offshore projects due to the low roughness on the ocean surface. Some of the recent studies which establish this effect in onshore and offshore wind farms can be found in [33]-[37]. For example, wake induced power deficit due to deep array effect is evident in large wind farms like Honsrev and Nysted as show in [38].

Modelling the wakes in large arrays of turbines and its impact on the atmospheric boundary layer is a complex problem as various properties of the atmosphere in the three-dimensional space must be incorporated in the models. Though these factors can be incorporated in sophisticated numerical modelling methods, accuracies of these approaches do not justify the demanding computational resources and costs. However, there are few attempts to define this phenomenon adopting simplified empirical approaches as discussed below.

One of the earlier thoughts on solving this complex problem was by Sten Frandsen [39], which was later brought forward further by him as seen in [19],[40]. In this approach, a large wind farm is considered as a region of high surface roughness caused by the turbines, which is uniformly distributed. This roughness results in drag and changes the structure of the planetary boundary layer (PBL). This reduces the free-stream wind velocity at the hub height of the turbines. Based on this theory, the windfarm equivalent roughness $\mathrm{Z}_{00}$ is given by

$$
z_{00}=h_{H} \exp \left(-\frac{\kappa}{\sqrt{c_{t}+\left(\kappa / \ln \left(h_{H} / z_{0}\right)\right)^{2}}}\right)
$$

Where, $h_{H}$ is the hub height, $k$ is the von Karman constant, $Z_{0}$ is the ambient roughness between turbines, and $C_{t}$ is the distributed thrust coefficient. The term $C_{t}$ is given by

$$
c_{t}=\frac{\pi}{8 s_{d} s_{c}} C_{T}
$$

where $C_{T}$ is the turbine thrust coefficient and $S_{d}$ and $S_{c}$ are the mean downwind and crosswind spacings in terms of rotor diameters. Once the equivalent roughness of the wind farm caused by turbines in large arrays are computed as above, the velocity deficit is calculated using the relationship

$$
\frac{v_{H}^{\prime}}{v_{H}}=\left(\frac{z_{00}}{z_{0}}\right)^{0.07} \frac{\ln \left(\begin{array}{l}
h_{H} / z_{00} \\
/ n
\end{array}\right)}{\ln \left(h_{H} / z_{0}\right)}
$$

Here, $V_{H}^{\prime}$ and $V_{H}$ are the hub-height wind speeds within the deep array and far upstream.

Starting from the concept proposed by Frandsen, a Deep Array Wake Model (DAWM) was developed and incorporated in wind farm design tools [33]. For this, Frandsen's theory was modified by incorporating the wake effects of individual turbines in the model. This helped in including array density and the effect of immediate upwind turbine in the model. Thus, each turbine assigned a separate area of increased surface roughness and as the wind flow passes a given turbine, an internal boundary layer with increased roughness is considered. This is further combined with another wake model, for example Eddy Viscosity (EV) model, to include the effect of immediate downstream wake impact of individual turbines. The outputs from individual turbines are estimated with both these models individually and the model giving highest wake losses is considered for further analysis. Thus, the turbine arrays in the wind farm is divided in to two, one with shallow wake zone where the conventional wake model is implemented and the other with deep wake zone where the roughness effects become dominant. The separation of these zones occurs typically about three rows in the flow direction [33],[41]. The models developed were tested with the production data from the Horns Rev wind farm and found to perform better than the conventional wake models [33]. A group of researchers from ECN reviewed various studies undertaken to estimate the wake effect of large wind farms due to the interaction between large turbines and the atmospheric boundary layer [42]. Wake interactions between neighboring wind farms was also looked in to. It has been observed that the velocity drop due to this two-way interaction would recover only after several (tens of) kilometers. 
All these studies clearly indicate the deep array effect in large wind farms and highlights the need for new approaches in understanding and quantifying the resulting power deficits.

\section{CONCLUSIONS}

Estimation on the power losses due to wake effect is essential in the efficient design and successful management of wind energy projects. Various models used for quantifying wake induced velocity deficit in wind farms and resulting power losses are reviewed in this paper. The deep array wake effect, which is prominent in large sized wind energy projects is also discussed. Though there are recent attempts to understand the deep array effect, a more rigorous investigation involving new approaches and methods are required to fully understand the effect of large turbines arrays on the atmospheric boundary layer, which basically causes the deep array effect and resulting power losses.

\section{ACKNOWLEDGMENT}

The first author is thankful to the Government of Brunei Darussalam for providing her with the Graduate Student Scholarship for the PhD programme.

\section{REFERENCES}

1. GWEC, Global Wind Reports 2018, Rep. 46-53, 2019.

2. https://ourworldindata.org/renewable-energy, 2019 [accessed 7th January 2020].

3. R. J. Barthelmie, K. Hansen, S. T. Frandsen, O. Rathmann, J. G. Schepers, W. Schlez, J. Phillips, K. Rados, A. Zervos and E.S Politis. "Modelling and measuring flow and wind turbine wakes in large wind farms offshore", Wind Energy, 2009, 12 (5), 431-444.

4. M. Gaumond, P. E Réthoré, A. Bechmann, S. Ott, G. C. Larsen, A. P. Diaz and K. S Hansen. "Benchmarking of wind turbine wake models in large offshore windfarms". In: The science of Making Torque from Wind, 2012 (4th scientific conference).

5. A. K Scholbrock. "Optimizing wind farm control strategies to minimize wake loss effects". University of Colorado at Boulder, 2011.

6. F. González-Longatt, P. Wall and V. Terzija. "Wake effect in wind farm performance: Steady-state and dynamic behavior". Renewable Energy, 2012, 39 (1), 329-338.

7. Y. Dalgic, I. Lazakis, I. Dinwoodie, D. McMillan, and M. Revie.”Advanced logistics planning for offshore wind farm operation and maintenance activities”. Ocean Engineering, 2015,101, 211-226.

8. A. S Bachhal and A. S Bachhal, 2017. "Optimization of Wind Farm Layout taking Load Constraints into Account”, 2017.

9. $\quad$ P. B. S Lissaman. "Energy effectiveness of arbitrary arrays of wind turbines". J. Energy, 1979, 3 (6), 323-328.

10. P. H Alfredsson and J. A Dahlberg. A Preliminary Wind Tunnel Study of Windmill Wake Dispersion in Various Flow Conditions, 1979.

11. M. B Anderson, D. J Milborrow, N. J Ross. "Performance and wake measurements on a $3 \mathrm{~m}$ diameter horizontal axis wind turbine: comparison of theory, wind tunnel and field test data". Department of Energy Energy Technology Support Unit; 1982 Apr.

12. C. G Helmis, K. H Papadopoulos, D. N Asimakopoulos, P. G Papageorgas and A. T Soilemes."An experimental study of the near-wake structure of a wind turbine operating over complex terrain". Solar energy, 1995, 54 (6), 413-428.

13. L. J Vermeer, J. N Sørensen and A. Crespo. "Wind turbine wake aerodynamics". Progress in aerospace sciences, 2003, 39 (6), 467-510.

14. M. Gaumond, P. E Réthoré, A. Bechmann, S.Ott, G. C Larsen, A. P Diaz and K. S Hansen. "Benchmarking of wind turbine wake models in large offshore windfarms". In: The science of Making Torque from Wind 2012: 4th scientific conference.

15. A. Keane, P. E. O Aguirre, H. Ferchland, P. Clive, and D.Gallacher. "An analytical model for a full wind turbine wake", In: Journal of Physics: Conference Series. IOP Publishing, 2016, 753(3), p. 32039.

16. P.E.J Vermeulen. "An experimental analysis of wind turbine wakes". In: 3rd international symposium on wind energy systems.1980, 431-450.

17. N. O Jensen. A note on wind generator interaction, 1983.

18. G. C Larsen, H. Madsen Aagaard, T.J Larsen and N. Troldborg. "Wake modeling and simulation. Danmarks Tekniske Universitet”, Risø Nationallaboratoriet for Bæredygtig Energi, 2008

19. S. Frandsen, R. Barthelmie, S. Pryor, O. Rathmann, S. Larsen, J. Højstrup and M. Thøgersen. " Analytical modelling of wind speed deficit in large offshore wind farms". Wind energy,2006, 9 (1-2), 39-53.

20. I. Katic, J. Højstrup and N. O Jensen. "A simple model for cluster efficiency". In: European wind energy association conference and exhibition, 1987, 407-410.

21. T. Sørensen and M. Thøgersen. "Adapting and calibration of existing wake models to meet the conditions inside offshore wind farms". EMD International A/S. Aalborg, 2008.

22. J. Choi and M. Shan. "Advancement of Jensen (Park) wake model”. In: Proceedings of the European Wind Energy Conference and Exhibition, 2013, 1-8.

23. J. Kollwitz. "Defining the Wake Decay Constant as a Function of Turbulence Intensity to Model Wake Losses in Onshore Wind Farms", 2016.

24. R. A Koch and J. B Lindberg. "Normal mode cycle distance and beam displacement, time delay, etc., for low (non-WKB) frequencies", The Journal of the Acoustical Society of America, 1985, 78 (3), 995-1002.

25. F. González-Longatt, P. Wall and V. Terzija. "Wake effect in wind farm performance: Steady-state and dynamic behavior", Renewable Energy, 2012, 39 (1), 329-338.

26. G. C Larsen, H. A Madsen and N.N Sørensen. "Mean wake deficit in the near field", In: 2003 European Wind Energy Conference and Exhibition. European Wind Energy Association (EWEA),2003.

27. O. Rathmann, R. Barthelmie and S. Frandsen. "Turbine wake model for wind resource software. In: European Wind Energy Conference", 2006

28. J. FAinslie."Calculating the flowfield in the wake of wind turbines". Journal of Wind Engineering and Industrial Aerodynamics,1988, 27 (1-3), 213-224.

29. D. Cabezón Martínez. "Development of a wake model for wind farms based on an open source CFD solver. Strategies on parabolization and turbulence modeling", Universidad Politécnica de Madrid ,2013.

30. J. D Anderson and J. Wendt. "Computational fluid dynamics". Springer, 1995.

31. M. Calaf, C. Meneveau and J. Meyers. "Large eddy simulation study of fully developed wind-turbine array boundary layers", Physics of fluids, 2010, 22 (1), 15110.

32. L. P Chamorro and F. Porte-Agel. "Turbulent flow inside and above a wind farm: a wind-tunnel study”. Energies, 2011, 4 (11), 1916-1936.

33. M. C Brower and N. M Robinson. "The openwind deep-array wake model: Development and validation", AWS Truepower, 2012.

34. R. J Barthelmie and L. E Jensen. "Evaluation of wind farm efficiency and wind turbine wakes at the Nysted offshore wind farm", Wind Energy, 2010,13 (6), 573-586.

35. W. Schlez and A. Neubert. "New developments in large wind farm modelling", Proceedings of EWEC 2009.

36. G. G Hassan. "WindFarmer V5.0. In: Validation Report", 2012

37. G. M Smith, A. Neubert, W. Schlez and G. G Hassan.’'Impact of Large Neighbouring Wind Farms on Energy Yield of Offshore Wind Farms", In: EWEA Offshore, 2011.

38. R. J. A. M Stevens, D. F Gayme and C. Meneveau. "Generalized coupled wake boundary layer model: applications and comparisons with field and LES data for two wind farms". Wind energy, 2016, 19 (11), 2023-2040.

39. S. Frandsen."'On the wind speed reduction in the center of large clusters of wind turbines. Journal of Wind Engineering and Industrial Aerodynamics",1992 39 (1-3), 251-265.

40. S. T Frandsen. "Turbulence and turbulence-generated structural loading in wind turbine clusters", 2007.

41. M. Filippelli. Applications of openWind, 2013.

42. E. T. G Bot, P. J Eecen and A. J Brand. "The influence of wind farms on the wind speed above the wind farms", Wind Energy, 2013. 


\section{AUTHORS PROFILE}

Veena Raj, completed her Bachelor's degree in Electronics \& Communication from the Anna University, Chennai, India and completed the Masters Programme in Applied Electronics from the Anna University, Chennai, India. These academic trainings motivated her to do further research and could complete her Doctoral degree in System Engineering from the Faculty of Integrated Technology, University of Brunei Darussalam. Focus of her research was on the application of Artificial Intelligence in designing and managing Renewable energy systems. In her Doctoral research, she could develop a short-term wind power forecasting system which can predict the performance of large wind farms with an impressive accuracy level. Five research papers based on this research has been published in different Scopus indexed platforms. Few more research papers on this work are under review. She also served as Assistant Professor at different Engineering Colleges under the Mahatma Gandhi University, Kerala, India.

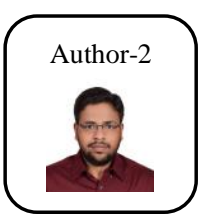

Manuel S $\mathbf{M}$ is an Electrical Engineer who is currently doing his masters in Renewable Energy in University of Agder, Norway. Previously, he was associated with the Energy Research Group at the Universiti Brunei Darussalam (UBD) as part of his master's research in Energy Systems Engineering. He has been involved in the power systems laboratory at UBD. His research interests include Grid Integration of Renewable Energy Systems, Electric Vehicles, Microgrids, Smart grids, Power System Dynamics, Energy Conversion and Management, and Energy Economics.

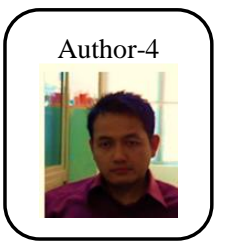

Dr Mohamad Iskandar Petra, obtained his BEng Honours degree and Master in Control Engineering from the University of Glasgow. In 2000 he joined Universiti Brunei Darussalam as academic staff. He then pursued his study and obtained his $\mathrm{PhD}$ in Biomedical Engineering from Aston University, Birmingham, United Kingdom. Since then he has actively doing research on multi-disciplinary areas including smart sensors to IOT, and advanced materials to energy. To date he has published over 50 technical papers most are Scopus indexed. He has 6 patents granted and one is filed. 